\title{
Ablation of C/SiC-HfC composite prepared by precursor infiltration and pyrolysis in plasma wind tunnel
}

\author{
Liuyang DUAN ${ }^{a}$, Lei $\mathrm{LUO}^{b}$, Liping $\mathrm{LIU}^{a, c}$, Yiguang $\mathrm{WANG}^{d, *}$ \\ ${ }^{a}$ Science and Technology on Thermostructural Composite Materials Laboratory, \\ Northwestern Polytechnical University, Xi'an 710072, China \\ ${ }^{b}$ Beijing Institute of Long March Aerospace Vehicles, Beijing 100076, China \\ ${ }^{c}$ Ultrahigh Speed Aerodynamics Research Institute, China Aerodynamics Research and \\ Development Center, Mianyang 621000, China \\ ${ }^{d}$ Institute of Advanced Structure Technology, Beijing Institute of Technology, \\ Haidian District, Beijing 100081, China
}

Received: December 23, 2019; Revised: March 14, 2020; Accepted: March 31, 2020

(C) The Author(s) 2020.

\begin{abstract}
Carbon fiber reinforced silicon carbide-hafnium carbide (C/SiC-HfC) composite was prepared by precursor infiltration and pyrolysis process. Then, ablation behavior of $\mathrm{C} / \mathrm{SiC}-\mathrm{HfC}$ was evaluated in plasma wind tunnel. It was found that oxide layer formed during ablation significantly influenced the surface temperature. Formation of dense $\mathrm{HfO}_{2}-\mathrm{SiO}_{2}$ layer under low heat flux led to stable surface temperature. Silica $\left(\mathrm{SiO}_{2}\right)$ on the surface was gradually consumed when heat flux increased, resulting in conversion of $\mathrm{HfO}_{2}-\mathrm{SiO}_{2}$ on the surface to $\mathrm{HfO}_{2}$. Converted $\mathrm{HfO}_{2}$ with high catalytic coefficient absorbed more energy, causing gradual increase in the surface temperature. Formed oxide layer was destroyed at high heat flux and high stagnation point pressure. After carbon fiber lost the protection of $\mathrm{HfO}_{2}-\mathrm{SiO}_{2}$ layer, it burned immediately, leading to surface temperature jump.
\end{abstract}

Keywords: $\mathrm{C} / \mathrm{SiC}-\mathrm{HfC}$ composite; precursor infiltration and pyrolysis; ablation; plasma wind tunnel

\section{Introduction}

During the hypersonic flight of vehicles in the atmosphere, a large amount of heat is generated due to the friction between vehicles and the atmosphere, causing the surface temperature of the vehicles to exceed $2000{ }^{\circ} \mathrm{C}[1,2]$. Thus, thermal protection systems (TPS) have become essential for hypersonic flights. Carbon fiber reinforced silicon carbide $(\mathrm{C} / \mathrm{SiC})$ composite

* Corresponding author.

E-mail: wangyiguang@bit.edu.cn is a promising TPS material due to its low density, high temperature resistance, ablation resistance, and other related fascinating properties [3-5]. However, active oxidation of $\mathrm{SiC}$ occurs at temperatures above $1700{ }^{\circ} \mathrm{C}$, which results in rapid failure of $\mathrm{C} / \mathrm{SiC}$ composite during service [6-8]. Therefore, modification of $\mathrm{C} / \mathrm{SiC}$ composite is necessary to meet the requirements of TPS applications at temperature above $1700{ }^{\circ} \mathrm{C}$.

An effective method for $\mathrm{C} / \mathrm{SiC}$ modification involves the introduction of ultrahigh temperature ceramics (UHTCs) into the matrix of $\mathrm{C} / \mathrm{SiC}$, forming $\mathrm{C} / \mathrm{SiC}-$ UHTCs composites $[9,10]$. The common UHTCs employed for $\mathrm{C} / \mathrm{SiC}$ modification are $\mathrm{ZrB}_{2}[11,12]$, 
$\mathrm{ZrC}[13,14], \mathrm{TaC}[15,16], \mathrm{HfB}_{2}[17,18]$, and $\mathrm{HfC}$ $[19,20]$. Among them, HfC not only has the highest melting point (about $3890{ }^{\circ} \mathrm{C}$ ), but also its oxide $\mathrm{HfO}_{2}$ has the highest melting point (about $2810{ }^{\circ} \mathrm{C}$ ) among the oxides of UHTCs [21,22]. Consequently, HfC was often introduced into $\mathrm{C} / \mathrm{SiC}$ composites as an ideal UHTC to form modified C/SiC-HfC composite. In our previous study [20], the influence of catalysis on the ablation behaviors of $\mathrm{C} / \mathrm{SiC}-\mathrm{HfC}$ composite prepared by reactive melt infiltration (RMI) was revealed. However, the diffusion mechanism of volatiles in ablation process is still not clear, which is related to the microstructures of $\mathrm{C} / \mathrm{SiC}-\mathrm{HfC}$ composites. For the comparative analysis of the diffusion mechanism of different microstructures during ablation, HfC phase used for modification was introduced via precursor infiltration and pyrolysis (PIP) process in this study, because PIP process has advantages such as easy designability of microstructures, low preparation temperature, and high mechanical properties of final composite, and uniform distribution of modified UHTCs [23-25]. However, reaction of $\mathrm{HfO}_{2}$ with carbon was involved in the formation of $\mathrm{HfC}$ from the precursor [26], which could lead to the damage of carbon fibers. Thus, $\mathrm{SiC}$ was first deposited on the preform by chemical vapor infiltration $(\mathrm{CVI})$ to reduce the damage to fibers caused by PIP process. Consequently, C/SiC-HfC composite was prepared by CVI and PIP in this study.

The methods used for the evaluation of ablation performance of above mentioned materials mainly include laser beam [27,28], oxy-acetylene flame [17, $25]$, arc-jet $[29,30]$, and plasma wind tunnel $[20,31]$. Plasma wind tunnel technique offers the advantage of measuring the change of the surface temperature compared to laser beam and oxy-acetylene flame methods. More importantly, plasma wind tunnel can provide a pure plasma flow [32]. On one hand, plasma must be considered during hypersonic flights, because the high temperature during flight can lead to the generation of plasma [33]. On the other hand, pure plasma flow can avoid the influence of impurities in wind tunnel, such as copper in the arc wind tunnel, and thus it is highly desirable to study the ablation mechanism of $\mathrm{C} / \mathrm{SiC}-\mathrm{HfC}$ composite. Therefore, plasma wind tunnel was selected as the method for evaluating the ablation performance of $\mathrm{C} / \mathrm{SiC}-\mathrm{HfC}$ composite and investigating the diffusion mechanism of volatiles in this study.

The phases and microstructures of $\mathrm{C} / \mathrm{SiC}-\mathrm{HfC}$ composite before and after ablation were systematically analyzed. Based on these analyses, the ablation mechanisms of $\mathrm{C} / \mathrm{SiC}-\mathrm{HfC}$ composite in plasma wind tunnel were proposed.

\section{Experimental}

Three-dimensional needled carbon fiber preform with $35 \%$ fiber volume fraction was prepared by needlepunching method with $\mathrm{T}-300^{\mathrm{TM}}$ alternatively stacked with weftless piles and short-cut-fiber webs. Pyrolytic carbon was deposited on the surface of fibers as interface layer by CVI process. Then, $\mathrm{SiC}$ was further deposited on the preform by CVI using methyltrichlorosilane as precursor to reduce the damage to fibers caused by subsequent processes. The density and open porosity of $\mathrm{C} / \mathrm{SiC}$ after deposition of the above mentioned layers were $1.56 \pm 0.03 \mathrm{~g} / \mathrm{cm}^{3}$ and $38.0 \% \pm 1.1 \%$, respectively. The $\mathrm{C} / \mathrm{SiC}$ preform was then machined into samples with $20 \mathrm{~mm}$ in diameter and $50 \mathrm{~mm}$ in length, as shown in Fig. 1(a).

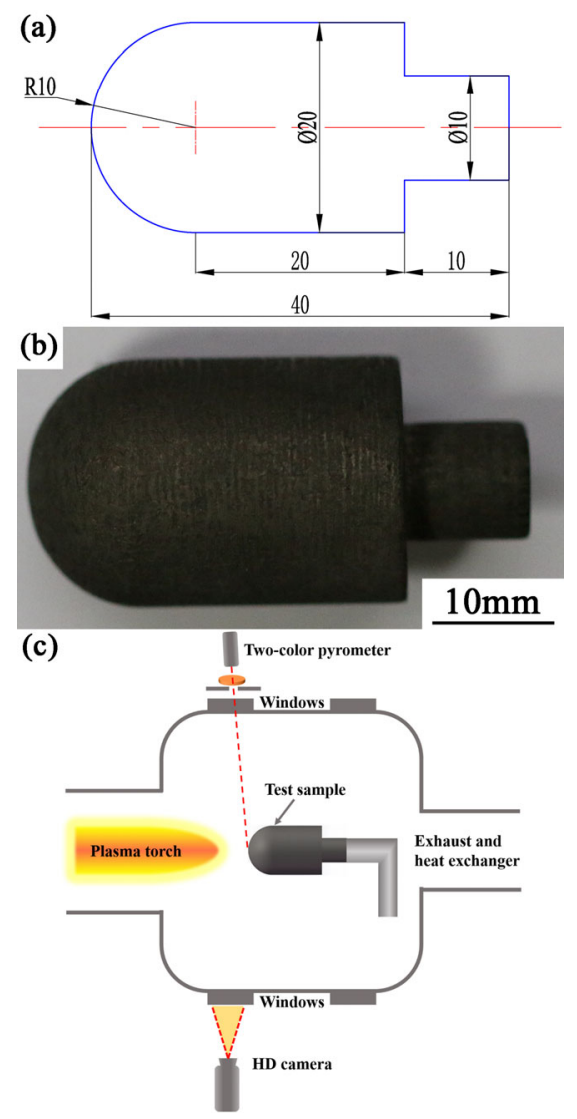

Fig. 1 Sample and plasma wind tunnel: (a) geometry of C/SiC-HfC; (b) morphology of C/SiC-HfC; (c) schematic representation of plasma wind tunnel. 
$\mathrm{C} / \mathrm{SiC}-\mathrm{HfC}$ composite was prepared by PIP process based on the as-prepared $\mathrm{C} / \mathrm{SiC}$ samples. In this process, liquid HfC precursor (Institute of Process Engineering, Chinese Academy of Sciences, Beijing, China) and solid polycarbosilane (PCS, Xiamen University, Xiamen, China) as SiC precursor were used. The ceramic yield of liquid $\mathrm{HfC}$ precursor was about $20 \mathrm{wt} \%$. More narrowly, the mass residue was $66.7 \%$ from liquid to solid at room temperature and $30 \%$ from solid to $\mathrm{HfC}$ after treatment at $1700{ }^{\circ} \mathrm{C}$ for $2 \mathrm{~h}$. The ceramic yield of solid PCS was about $50 \mathrm{wt} \%$ after treatment at $1700{ }^{\circ} \mathrm{C}$ for $2 \mathrm{~h}$. The xylene solution of PCS (50\% mass concentration) was first mixed with $\mathrm{HfC}$ precursor at a mass ratio of 33:100 to obtain the final molar ratio of $\mathrm{SiC}: \mathrm{HfC}$ as $2: 1$, which is the same as for $\mathrm{C} / \mathrm{SiC}-\mathrm{HfC}$ composite prepared by RMI process [20], and thus it was convenient to compare the ablation behaviors of the two composites. The mixed precursors were introduced into the as-prepared $\mathrm{C} / \mathrm{SiC}$ samples by vacuum pressure impregnation (VPI). Subsequently, the impregnated samples were dried at room temperature for $12 \mathrm{~h}$ and then pyrolyzed at $1500{ }^{\circ} \mathrm{C}$ for $2 \mathrm{~h}$. After eight circles of VPI and pyrolysis, the resultant samples were heat treated at $1700{ }^{\circ} \mathrm{C}$ for $2 \mathrm{~h}$ in vacuum, ensuring complete reaction between $\mathrm{HfO}_{2}$ and carbon to form HfC. The open porosities of samples increased after heat treatment. Thus, the samples were further densified by VPI and pyrolysis. The final $\mathrm{C} / \mathrm{SiC}-\mathrm{HfC}$ composite samples were obtained after four heat treatment cycles, as shown in Fig. 1(b).

The ablation characteristics of $\mathrm{C} / \mathrm{SiC}-\mathrm{HfC}$ composite were tested in a high-frequency plasma wind tunnel (1 MW, Ultrahigh Speed Aerodynamics Research Institute, China Aerodynamics Research and Development Center, China), whose schematic illustration is presented in Fig. 1(c). The velocity of plasma gas was set to be 0.7 Mach. The volumetric proportions of oxygen and nitrogen in plasma gas were $21 \%$ and $79 \%$, respectively, in accordance with the air environment. The distance between samples and torch exit was set as $600 \mathrm{~mm}$. The temperature changes during the ablation process were measured using an infrared pyrometer with $\pm 20{ }^{\circ} \mathrm{C}$ accuracy and $500-2500{ }^{\circ} \mathrm{C}$ range. More detailed descriptions of plasma wind tunnel can be found in literature report [20].

The density and porosity of samples were measured by Archimedes drainage method. The crystal phases of samples were characterized by X-ray diffraction (XRD, $\mathrm{Cu} \mathrm{K} \alpha$, RigakuD/Max-2400, Tokyo, Japan). The scanning rate and scanning range were $0.12\left(^{\circ}\right) / \mathrm{s}$ and $10^{\circ}-80^{\circ}$ respectively. The microstructures of samples were analyzed by scanning electron microscopy (SEM, JEOL 6700F, Tokyo, Japan) system equipped with energy dispersive spectrometer (EDS), which was used to investigate the sample composition.

\section{Results and discussion}

The densities and open porosities of final $\mathrm{C} / \mathrm{SiC}-\mathrm{HfC}$ samples obtained by PIP process were $3.18 \pm 0.04 \mathrm{~g} / \mathrm{cm}^{3}$ and $13.2 \% \pm 0.4 \%$, respectively. Figure 2 exhibits XRD patterns of sample, showing the existence of $\mathrm{SiC}$ and $\mathrm{HfC}$ phases and indicating successfully introduction of $\mathrm{HfC}$ into the porous $\mathrm{C} / \mathrm{SiC}$ composite and no impurities were introduced after the PIP process. The volume fraction of $\mathrm{HfC}$ phase can be calculated as follows:

$$
V_{\mathrm{H}}=\frac{V_{\mathrm{mf}}}{V_{\mathrm{mf}}+2 V_{\mathrm{ms}}}\left(P_{\mathrm{r}}-P_{\mathrm{f}}\right)
$$

where $V_{\mathrm{H}}$ represents the volume fraction of HfC phase in $\mathrm{C} / \mathrm{SiC}-\mathrm{HfC}$ composite; $V_{\mathrm{mf}}$ and $V_{\mathrm{ms}}$ represent the molar volumes of $\mathrm{HfC}$ and $\mathrm{SiC}$, which are 15.3 and $12.5 \mathrm{~cm}^{3} / \mathrm{mol}$ respectively; $P_{\mathrm{r}}$ and $P_{\mathrm{f}}$ represent open porosities of initial $\mathrm{C} / \mathrm{SiC}$ preforms and final $\mathrm{C} / \mathrm{SiC}-$ $\mathrm{HfC}$ composite, which are $38 \%$ and $13.2 \%$ respectively. Thus, the volume fraction of $\mathrm{HfC}$ in $\mathrm{C} / \mathrm{SiC}-\mathrm{HfC}$ composite is about $9.4 \%$.

The backscatter images of cross-sectional microstructures for the $\mathrm{C} / \mathrm{SiC}-\mathrm{HfC}$ composite are shown in Fig. 3. Clearly, the carbon fibers were protected by the surrounding $\mathrm{SiC}$ layer deposited by CVI process, and no fiber corrosion was observed. The $\mathrm{SiC}$ and $\mathrm{HfC}$ phases introduced by PIP were filled between the fiber bundles as the matrix of $\mathrm{C} / \mathrm{SiC}-\mathrm{HfC}$

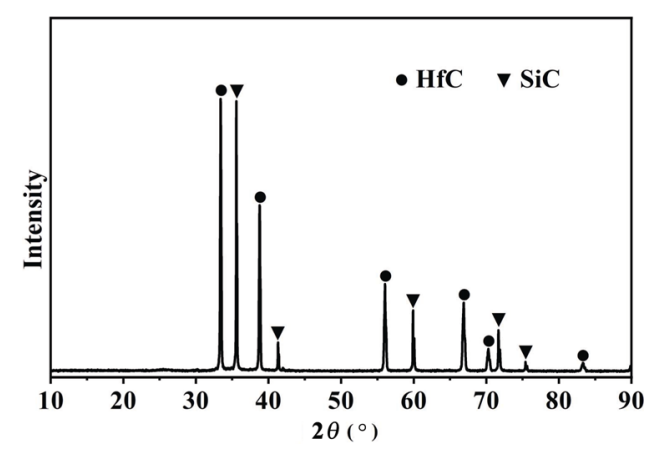

Fig. 2 XRD pattern of $\mathrm{C} / \mathrm{SiC}-\mathrm{HfC}$ composite prepared by PIP process. 


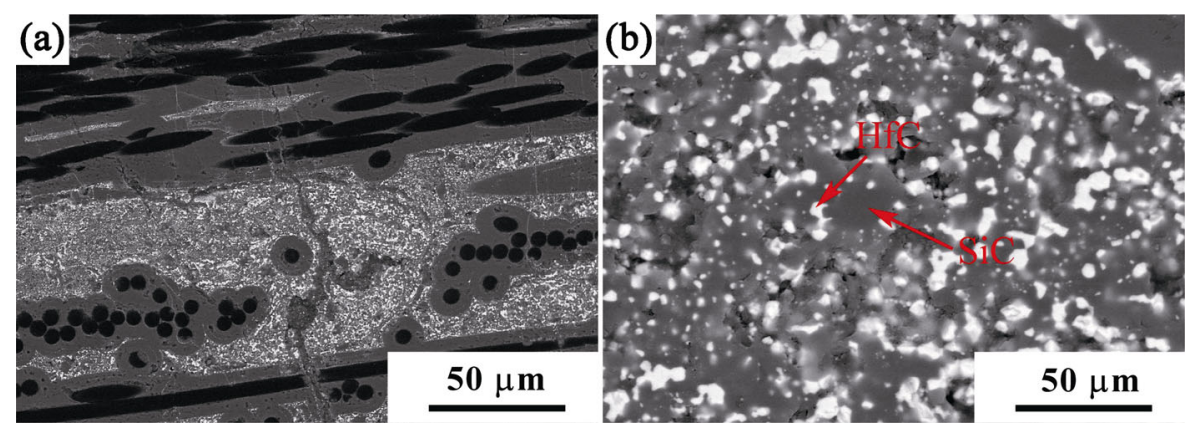

Fig. 3 Internal microstructures of $\mathrm{C} / \mathrm{SiC}-\mathrm{HfC}$ composite.

composite. The HfC phase was uniformly distributed in $\mathrm{SiC}$ phase formed from PCS, because the liquid HfC precursor and xylene solution of PCS were mixed at the molecular scale. Figure 3(b) also shows the presence of some micropores, which could be due to the processes of drying and pyrolysis of precursors involving volume contraction.

Four $\mathrm{C} / \mathrm{SiC}-\mathrm{HfC}$ composite samples were tested under four different conditions in the plasma wind tunnel, which was the same as our previous study [20], in order to compare the results. The main parameters included cold-wall heat flux $q_{\mathrm{cw}}$ and stagnation point pressure $P_{\mathrm{s}}$, which ranged in $3.5-5.1 \mathrm{MW} / \mathrm{m}^{2}$ and 4.5-6.2 $\mathrm{kPa}$, respectively. The sample temperatures varied with the ablation conditions. The steady wall temperature and the maximum temperature were denoted as $T_{\mathrm{w}}$ and $T_{\mathrm{m}}$, respectively. Detailed parameters of the four ablation conditions labeled as HF1 to HF4, and the ablation rates including mass ablation rate and linear ablation rate are listed in Table 1 . The ablation rate increased with the increase in heat flux and stagnation point pressure. The sample expanded slightly at low heat flux due to oxidation of $\mathrm{SiC}$ and HfC. In contrast, ablation resulted in the shortening of the sample at high heat flux.

Figure 4 demonstrates the variations of temperature with ablation time, exhibiting the rapid increase in the surface temperature after samples were exposed to heat flow. Then, the surface temperature under HF1 and HF2 conditions reached the maximum and remained stable during the ablation process. Higher value of $P_{\mathrm{s}}$ resulted in higher surface temperature at the same heat flux. This is attributed to the fact that a higher pressure would cause more energy to reach the surface of the sample. Different from HF1 and HF2 samples, the surface temperature of HF3 sample first reached a steady-state, then gradually increased, and finally reached another steady-state. The final temperature was about $2454{ }^{\circ} \mathrm{C}$. When the heat flux was further increased to $5.1 \mathrm{MW} / \mathrm{m}^{2}$, namely the sample $\mathrm{HF} 4$, a sudden temperature jump occurred at about $40 \mathrm{~s}$ during the ablation process. The temperature after jump was above $2500{ }^{\circ} \mathrm{C}$, which could not be accurately measured in this experiment due to the limitation of infrared temperature measurement. Besides, the surface temperature of HF4 dropped slightly before the jump. In order to protect the surface microstructures of sample, the ablation

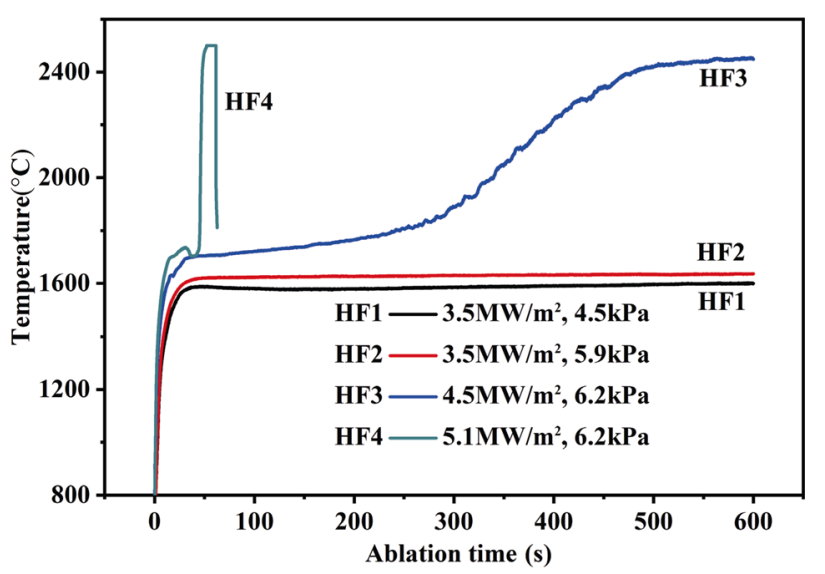

Fig. 4 Variations of surface temperature with time for $\mathrm{C} / \mathrm{SiC}-\mathrm{HfC}$ composite under different ablation conditions.

Table 1 Response parameters of $\mathrm{C} / \mathrm{SiC}-\mathrm{HfC}$ composite to different conditions

\begin{tabular}{cccccccc}
\hline Condition & $q_{\mathrm{cw}}\left(\mathrm{MW} / \mathrm{m}^{2}\right)$ & $P_{\mathrm{s}}(\mathrm{kPa})$ & $T_{\mathrm{w}}\left({ }^{\circ} \mathrm{C}\right)$ & $T_{\mathrm{m}}\left({ }^{\circ} \mathrm{C}\right)$ & Time $(\mathrm{s})$ & Mass ablation rate $(\mathrm{g} / \mathrm{s})$ & Linear ablation rate $(\mathrm{mm} / \mathrm{s})$ \\
\hline $\mathrm{HF} 1$ & $3.5 \pm 0.1$ & 4.5 & 1591 & - & 600 & $7.32 \times 10^{-6}$ & $-2.50 \times 10^{-4}$ \\
$\mathrm{HF} 2$ & $3.5 \pm 0.1$ & 5.9 & 1632 & - & 600 & $1.16 \times 10^{-5}$ & $-5.00 \times 10^{-5}$ \\
$\mathrm{HF} 3$ & $4.5 \pm 0.1$ & 6.2 & 1706 & 2454 & 600 & $8.66 \times 10^{-4}$ & $6.67 \times 10^{-5}$ \\
$\mathrm{HF} 4$ & $5.1 \pm 0.1$ & 6.2 & 1735 & 2500 & 60 & $1.99 \times 10^{-3}$ & $3.33 \times 10^{-4}$ \\
\hline
\end{tabular}


process was stopped immediately after the temperature jump.

The macroscopic images of $\mathrm{C} / \mathrm{SiC}-\mathrm{HfC}$ composite after ablation are shown in Fig. 5. When the heat fluxes were 3.5 and $4.5 \mathrm{MW} / \mathrm{m}^{2}$, a white oxide covered the sample surface and no fiber was exposed, although the surface temperature of the sample reached $2454{ }^{\circ} \mathrm{C}$ at heat flux of $4.5 \mathrm{MW} / \mathrm{m}^{2}$. This indicated that $\mathrm{C} / \mathrm{SiC}-$
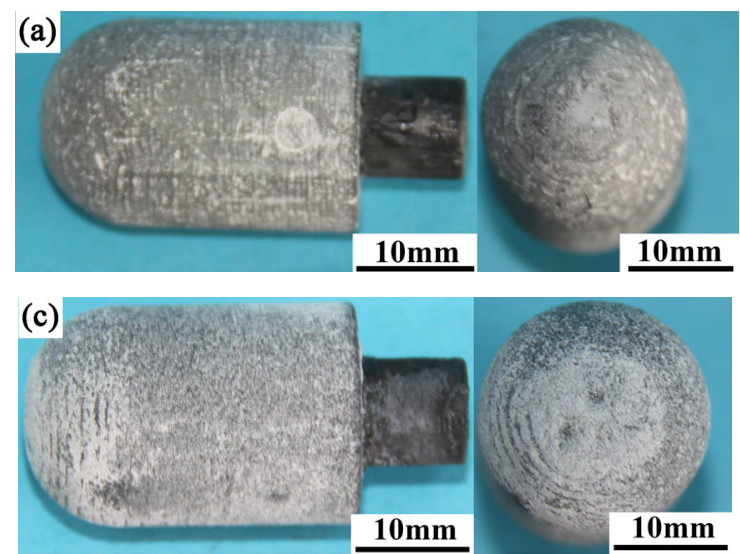

HfC composite prepared by PIP exhibited good ablation resistance under these ablation conditions. When the heat flux was further increased to $5.1 \mathrm{MW} / \mathrm{m}^{2}$, the fibers at the stagnation point were obviously ablated, which showed that the sample failed during the ablation process.

Figure 6 shows the surface microstructures of the stagnation point region after ablation, exhibiting the

Fig. 5 Macroscopic images of C/SiC-HfC composite after ablation: (a) HF1; (b) HF2; (c) HF3; (d) HF4.
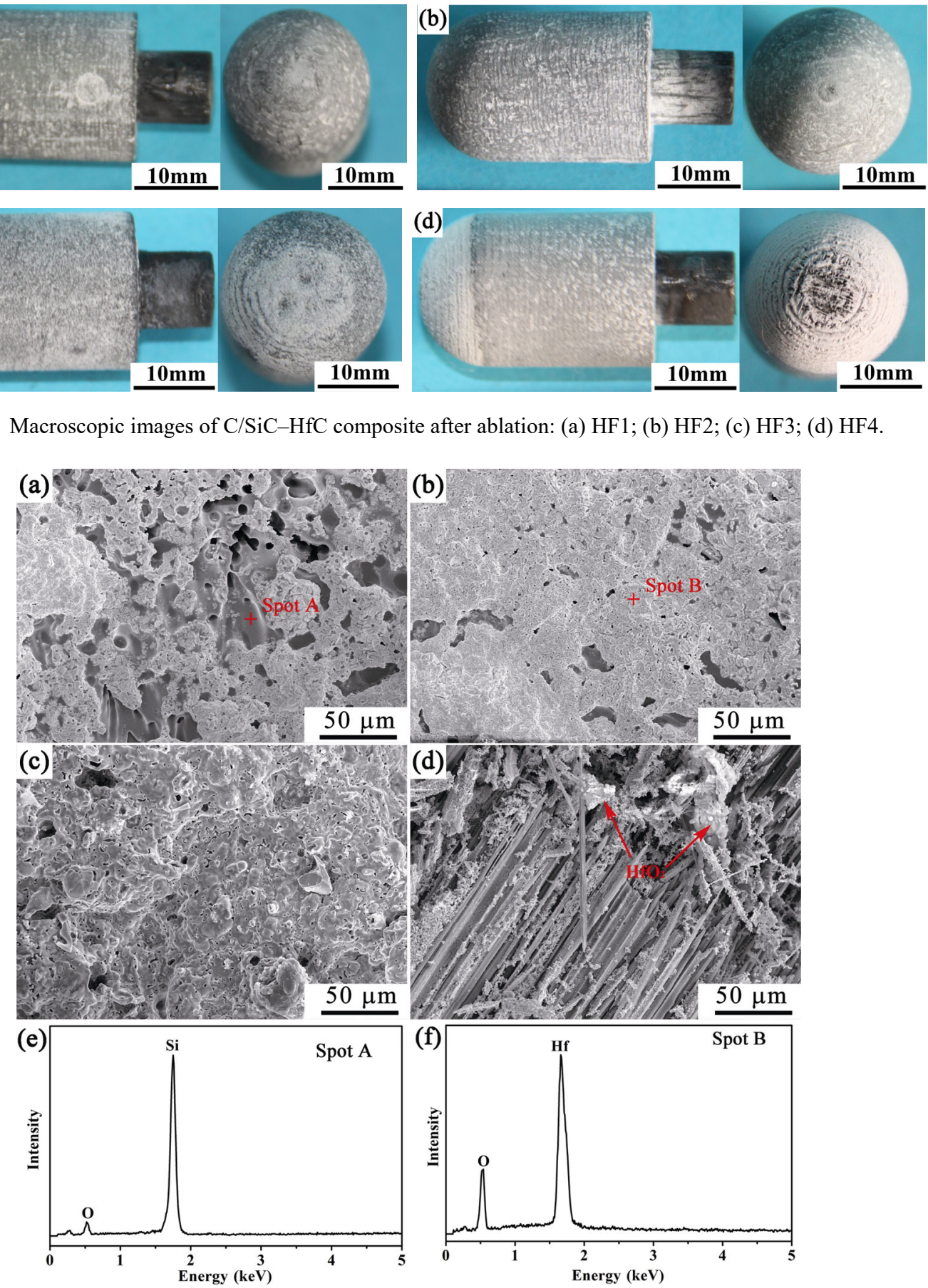

Fig. 6 Surface microstructures of C/SiC-HfC composite after ablation: (a) HF1; (b) HF2; (c) HF3; (d) HF4; (e) EDS analysis of spot A in HF1; (f) EDS analysis of spot B in HF2. 
coating of the oxide layers on the surface of samples HF1-HF3 and no fibers are exposed after ablation. A few holes were observed on the surface of HF1. Considering that the surface after ablation was not machined and the stagnation point pressure in this state was low, the holes resulted from oxidation of fibers in short-cut-fiber webs. The oxide layers of HF1 and HF2 were clearly composed of $\mathrm{SiO}_{2}$ and $\mathrm{HfO}_{2}$ formed due to oxidation of $\mathrm{SiC}$ and $\mathrm{HfC}$, respectively. Further, the content of $\mathrm{SiO}_{2}$ on the surface decreased with the increase in ablation temperature. No $\mathrm{SiO}_{2}$ was found on the surface of sample HF3, due to high temperature during the ablation process. Different from HF1-HF3, fibers of sample HF4 were uncovered and exhibited severe ablation. $\mathrm{HfO}_{2}$ was detected among the fiber bundles and no $\mathrm{SiO}_{2}$ was found in the stagnation point region after ablation.

The cross-section microstructures of HF1-HF3 in the stagnation point region are shown in Fig. 7. A thick $\mathrm{SiO}_{2}-\mathrm{HfO}_{2}$ layer was observed in all three samples. The oxide layers of HF1 and HF2 were consistent with the above mentioned results of above surface analysis. In contrast, large amounts of $\mathrm{SiO}_{2}$ were observed in the cross-section microstructure of $\mathrm{HF} 3$, while $\mathrm{SiO}_{2}$ was not found on the surface of the same sample. Moreover, there were some voids in the oxide layer, which got enlarged in sample HF3 and formed larger holes.

Based on the above mentioned observations and results of our previous study [20], the ablation behaviors of $\mathrm{C} / \mathrm{SiC}-\mathrm{HfC}$ prepared by PIP process can be explained as follows (Fig. 8). At heat flux of $3.5 \mathrm{MW} / \mathrm{m}^{2}$, the ablation behaviors of $\mathrm{C} / \mathrm{SiC}-\mathrm{HfC}$ composites were independent of the preparation methods and similar to the oxidation of UHTCs $[34,35]$. HfC and $\mathrm{SiC}$ on the surface of the sample were first oxidized during the ablation process to form $\mathrm{HfO}_{2}$ and $\mathrm{SiO}_{2}$, respectively.
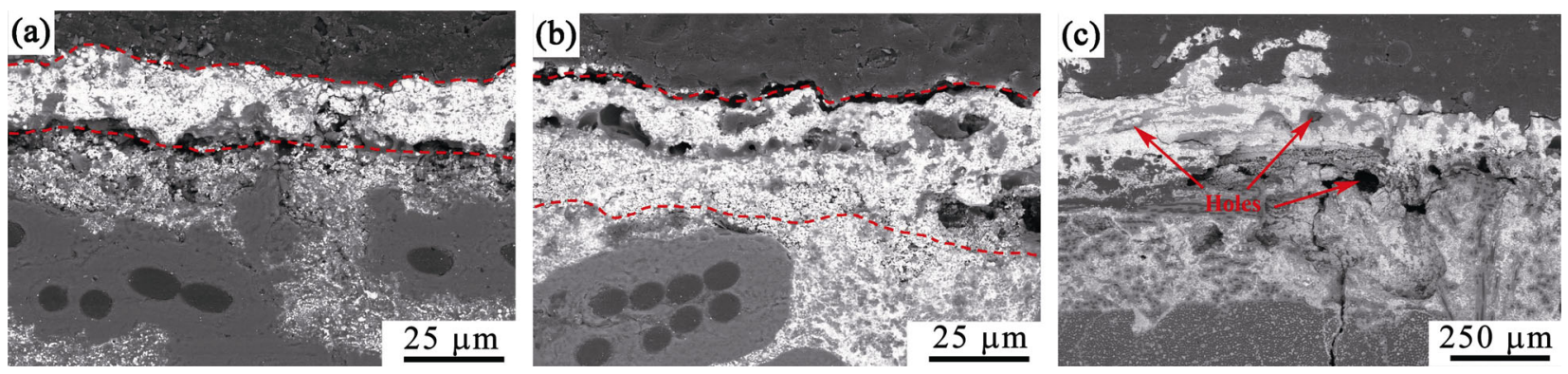

Fig. 7 Cross-section microstructures of C/SiC-HfC composite after ablation: (a) HF1; (b) HF2; (c) HF3.

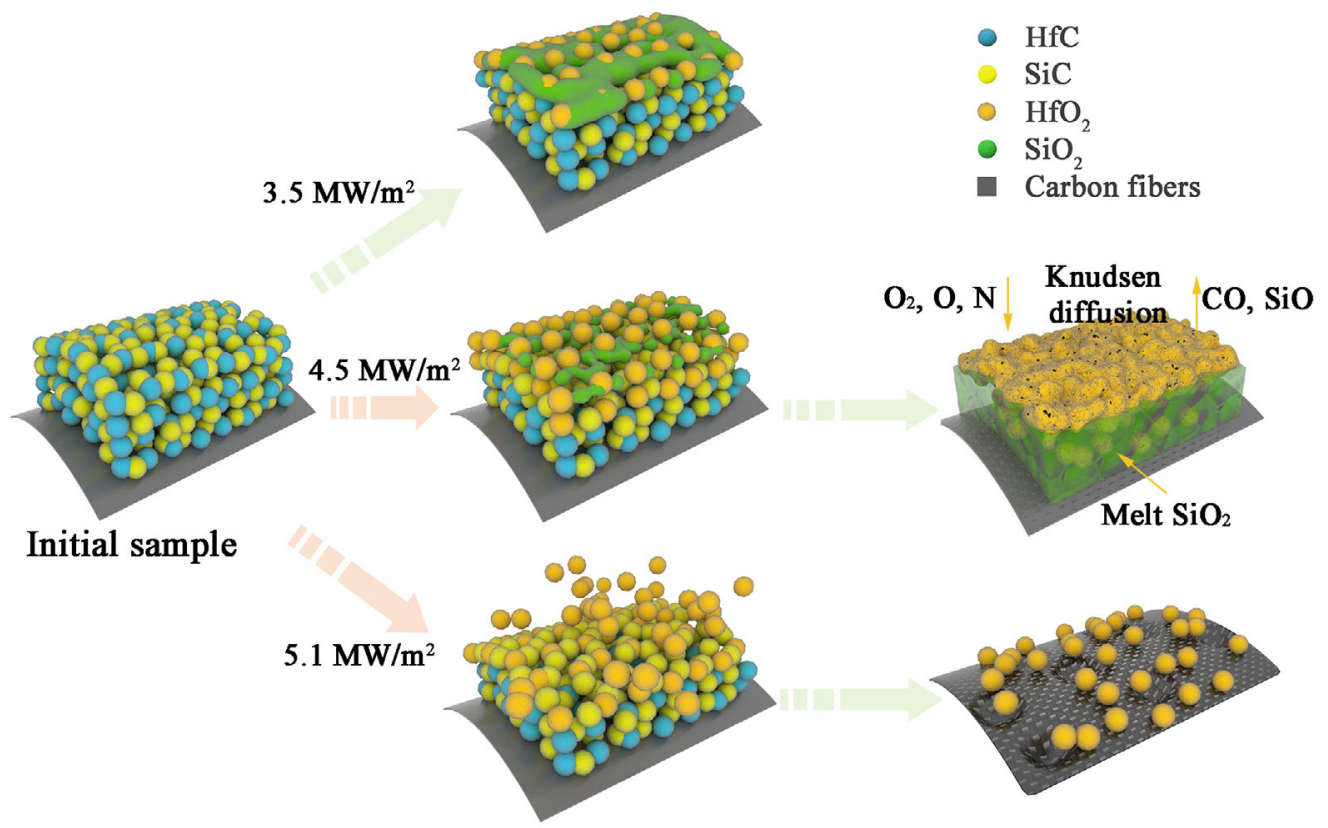

Fig. 8 Ablation mechanisms of $\mathrm{C} / \mathrm{SiC}-\mathrm{HfC}$ composite under different ablation conditions. 
The formed $\mathrm{HfO}_{2}$ has a high melting point (about $\left.2810{ }^{\circ} \mathrm{C}\right)$. Thus, it acted as a porous solid skeleton during ablation. $\mathrm{SiO}_{2}$ with a low melting point was filled in the $\mathrm{HfO}_{2}$ skeleton in liquid state. The liquid $\mathrm{SiO}_{2}$ and $\mathrm{HfO}_{2}$ skeleton formed the oxide layer, protecting the substrate from further ablation. Then, oxygen diffused from the surface of sample to the substrate through the oxide layer, while silicon oxide diffused from the oxide layer to the surface $[20,36]$. $\mathrm{SiO}_{2}$ on the surface would be lost under the combined effects of atomic oxygen, high-temperature, and highspeed flow [37]. Besides, the active oxidation of $\mathrm{SiC}$ likely occurred under the $\mathrm{HfO}_{2}-\mathrm{SiO}_{2}$ layer due to lower oxygen partial pressure here, which may be one of the reasons for the formation of voids under the oxide layer. The loss of $\mathrm{SiO}_{2}$ and oxidation of $\mathrm{SiC}$ led to consumption of $\mathrm{SiC}$, and finally caused mass loss after ablation. However, owing to the low heat flux, the consumption rate of $\mathrm{SiC}$ was low and the $\mathrm{HfO}_{2}-\mathrm{SiO}_{2}$ layer could protect the substrate composite for a long time.

When the heat flux of ablation increased to $4.5 \mathrm{MW} / \mathrm{m}^{2}$, a unique phenomenon was observed. The surface temperature of $\mathrm{C} / \mathrm{SiC}-\mathrm{HfC}$ composites reached a stable stage, then gradually increased, and finally reached another stable stage. This phenomenon was not found during ablation under the same conditions for $\mathrm{C} / \mathrm{SiC}$ composite prepared by $\mathrm{CVI}$ process and $\mathrm{C} / \mathrm{SiC}-\mathrm{HfC}$ composite prepared by RMI process [20,31,37]. Considering that there was no significant change in energy output (mainly including radiation and conduction) from the sample after the temperature reached the first stable stage, the energy arriving at the sample likely increased, and eventually caused the surface temperature of the sample to rise. It is known that the flow in plasma wind tunnel contains molecular oxygen and atomic oxygen (dissociated oxygen) [38]. When the atomic oxygen reached the surface of material, it was partially converted to molecular oxygen. The ratio of converted atomic oxygen to total atomic oxygen is defined as catalytic coefficient $\gamma$ [39]. The conversion is exothermic, and thus higher catalytic coefficient of the material causes higher amount of energy to reach the surface of the sample. Our previous study [20] found that when the sample surface composition changed from $\mathrm{SiO}_{2}$ with low catalytic coefficient to $\mathrm{HfO}_{2}$ with high catalytic coefficient, it caused the sample to absorb more heat from plasma gas, causing a jump of temperature on the sample surface. However, the temperature jump was not observed for the
$\mathrm{C} / \mathrm{SiC}-\mathrm{HfC}$ composite prepared by PIP and a gradual temperature change was found instead. Consequently, it can be inferred that a gradual change of the sample surface $\mathrm{SiO}_{2}$ to $\mathrm{HfO}_{2}$ led to increase in the surface catalytic coefficient, and eventually caused gradual increase in surface temperature of samples.

The microstructure of C/SiC-HfC by PIP (Fig. 3(b)) indicated that $\mathrm{HfC}$ had a small size $(<2 \mu \mathrm{m})$ and was uniformly dispersed in $\mathrm{HfC}-\mathrm{SiC}$ matrix. During ablation, $\mathrm{HfC}$ was oxidized to form $\mathrm{HfO}_{2}$ skeleton, through which $\mathrm{SiC}$ was oxidized and consumed. Owing to the small size and uniform distribution of $\mathrm{SiC}$, the formed passages for the diffusion of oxidative species and silicon oxide in $\mathrm{HfO}_{2}$ skeleton were less than $2 \mu \mathrm{m}$ in size. The results of Holcomb's study [40] showed that when the pore size of diffusion medium was less than $10 \mu \mathrm{m}$, the effect of Knudsen diffusion could not be ignored, and increased with the decrease of pore size. Yang et al. [41] reported that Knudsen diffusion tended to contribute dominantly when the average pore size of diffusion medium was $2 \mu \mathrm{m}$. Thus, the similar pore size in $\mathrm{HfO}_{2}$ skeleton was small enough to enable Knudsen diffusion for the outward species of silicon oxide. Knudsen diffusion with much lower diffusion rate than molecular diffusion retarded the erosion rate of $\mathrm{SiC}$ at the heat flux of $4.5 \mathrm{MW} / \mathrm{m}^{2}$. Moreover, the silica in the top oxide layer during ablation was gradually consumed and finally transferred into pure $\mathrm{HfO}_{2}$ as shown in Fig. 6(c). In this case, the surface catalytic coefficient should slowly increase to the value of pure $\mathrm{HfO}_{2}$, which should respond to the high temperature at final stage. This was confirmed by the fact that the final stable surface temperature of HF3 sample was $2454{ }^{\circ} \mathrm{C}$, similar to the reported temperature of ablation for $\mathrm{HfC}$-based ceramics in arc-jet or plasma wind tunnel $\left(2400{ }^{\circ} \mathrm{C}\right)$ [42]. At such a high temperature, $\mathrm{HfO}_{2}$ on the surface was sintered, and some holes with size less than $2 \mu \mathrm{m}$ were left, as shown in Fig. 6(c). This was because that the Tammann temperature of $\mathrm{HfO}_{2}$ was about $2000{ }^{\circ} \mathrm{C}$ (about 0.75 of its melting point [43]), lower than the final stable surface temperature. However, the whole $\mathrm{HfO}_{2}$ porous network could still be stable for some time due to the temperature gradient in the oxide layer. Furthermore, $\mathrm{SiO}_{2}$ was filled in the porous $\mathrm{HfO}_{2}$ structure, as shown in Fig. 7(c). The stable $\mathrm{HfO}_{2}$ porous network provided channels for Knudsen diffusion, which retarded the loss of $\mathrm{SiO}_{2}$ in the $\mathrm{HfO}_{2}-\mathrm{SiO}_{2}$ layer.

When the heat flux was further increased to 
$5.1 \mathrm{MW} / \mathrm{m}^{2}$, a jump in surface temperature occurred during the ablation process. The temperature jump was also found during the ablation of $\mathrm{C} / \mathrm{SiC}-\mathrm{HfC}$ prepared by $\mathrm{RMI}$ and $\mathrm{C} / \mathrm{SiC}$ under high heat flux condition [20,31,37]. When the sample HF4 was moved into the plasma flow, the surface temperature rapidly climbed to $1735{ }^{\circ} \mathrm{C}$. The atomic oxidation of $\mathrm{SiC}$ and $\mathrm{HfC}$ occurred under this condition, similar to that of HF1 and HF2 at low heat flux. The Knudsen diffusion of outward silicon oxide was still believed to be the controlling process. However, higher heat flux for HF4 samples resulted in a faster loss of $\mathrm{SiO}_{2}$ than that for HF3. The outward diffusion of silicon oxide was not fast enough to catch up its consumption in the top layer, leaving the pure $\mathrm{HfO}_{2}$ to face the plasma flow. High catalytic surface of $\mathrm{HfO}_{2}$ could lead to the rapid increase in temperature, in turn accelerating the consumption of $\mathrm{SiO}_{2}$ in the top layer to form loose $\mathrm{HfO}_{2}$, which was likely scoured away by the high-speed flow. After the coating on $\mathrm{C} / \mathrm{SiC}-\mathrm{HfC}$ was ablated away, the carbon fiber directly faced the plasma flow and began to burn. The burning of fibers included not only the reaction between $\mathrm{C}$ and $\mathrm{O}_{2}$, but also reactions of $\mathrm{C}$ with atomic $\mathrm{O}$ and $\mathrm{N}$, which exhibited faster reaction rates $[44,45]$. A large amount of heat was released by the burning of fibers, which finally caused a jump in the surface temperature. After the temperature jumped, $\mathrm{SiC}$ was decomposed rapidly at temperature above $2500{ }^{\circ} \mathrm{C}$ and the remaining HfC that was not scoured was oxidized to $\mathrm{HfO}_{2}$, as shown in Fig. 6(d). However, the final temperature (after jumping) during ablation of $\mathrm{C} / \mathrm{SiC}$ prepared by $\mathrm{CVI}$ [37] and final temperature of HF3 were lower than $2500{ }^{\circ} \mathrm{C}$. Therefore, the temperature jump was likely due to the synergy between carbon fiber combustion and the catalysis of $\mathrm{HfO}_{2}$. The residual $\mathrm{HfO}_{2}$ absorbed more energy during ablation due to its high catalytic coefficient and in turn accelerated the burning of carbon fibers.

\section{Conclusions}

$\mathrm{C} / \mathrm{SiC}-\mathrm{HfC}$ composite was successfully prepared by precursor infiltration and pyrolysis process. The ablation behavior of the $\mathrm{C} / \mathrm{SiC}-\mathrm{HfC}$ composite was studied in plasma wind tunnel. The results showed that the synergistic effect between the stable $\mathrm{HfO}_{2}$ porous network and the sustainable diffusion of silicon oxide played a crucial role in the ablation process. The low diffusion rates of oxygen and silicon oxide through the $\mathrm{HfO}_{2}-\mathrm{SiO}_{2}$ layer at heat flux of $3.5 \mathrm{MW} / \mathrm{m}^{2}$ led to a good ablation performance. $\mathrm{SiO}_{2}$ was gradually removed through Knudsen diffusion when the heat flux was increased to $4.5 \mathrm{MW} / \mathrm{m}^{2}$. The stable $\mathrm{HfO}_{2}$ porous network stabilized by $\mathrm{SiO}_{2}$ provided the channel for Knudsen diffusion. At heat flux of $5.1 \mathrm{MW} / \mathrm{m}^{2}$, the stable network was destroyed due to the rapid oxidation of $\mathrm{SiC}$ and the scouring of $\mathrm{HfO}_{2}$. The subsequent burning of carbon fibers and the catalysis of $\mathrm{HfO}_{2}$ caused temperature jump conjointly. Therefore, this study provides a reference for the microstructure control of composites used in TPS.

\section{Acknowledgements}

The authors greatly acknowledge the financial support from the National Natural Science Foundation of China (Grant No. 51972027).

\section{References}

[1] Squire TH, Marschall J. Material property requirements for analysis and design of UHTC components in hypersonic applications. J Eur Ceram Soc 2010, 30: 2239-2251.

[2] Glass DE. Ceramic matrix composite (CMC) thermal protection systems (TPS) and hot structures for hypersonic vehicles. In: Proceedings of the 15th AIAA International Space Planes and Hypersonic Systems and Technologies Conference, 2008: AIAA-2008-2682.

[3] Ma QS, Cai LH. Fabrication and oxidation resistance of mullite/yttrium silicate multilayer coatings on $\mathrm{C} / \mathrm{SiC}$ composites. J Adv Ceram 2017, 6: 360-367.

[4] Xu YD, Zhang LT, Cheng LF, et al. Microstructure and mechanical properties of three-dimensional carbon/silicon carbide composites fabricated by chemical vapor infiltration. Carbon 1998, 36: 1051-1056.

[5] Krenkel W, Berndt F. C/C-SiC composites for space applications and advanced friction systems. Mat Sci Eng A 2005, 412: 177-181.

[6] Sakraker I, Asma CO. Experimental investigation of passive/active oxidation behavior of $\mathrm{SiC}$ based ceramic thermal protection materials exposed to high enthalpy plasma. J Eur Ceram Soc 2013, 33: 351-359.

[7] Balat MJH. Determination of the active-to-passive transition in the oxidation of silicon carbide in standard and microwave-excited air. J Eur Ceram Soc 1996, 16: 55-62.

[8] Vaughn WL, Maahs HG. Active-to-passive transition in the oxidation of silicon carbide and silicon nitride in air. $J \mathrm{Am}$ Ceram Soc 1990, 73: 1540-1543.

[9] Opeka MM, Talmy IG, Zaykoski JA. Oxidation-based 
materials selection for $2000{ }^{\circ} \mathrm{C}+$ hypersonic aerosurfaces: Theoretical considerations and historical experience. $J$ Mater Sci 2004, 39: 5887-5904.

[10] Arai Y, Inoue R, Goto K, et al. Carbon fiber reinforced ultra-high temperature ceramic matrix composites: A review. Ceram Int 2019, 45: 14481-14489.

[11] Zhao X, Wang YG, Duan LY, et al. Improved ablation resistance of $\mathrm{C} / \mathrm{SiC}-\mathrm{ZrB}_{2}$ composites via polymer precursor impregnation and pyrolysis. Ceram Int 2017, 43: 12480-12489.

[12] Gui KX, Liu FY, Wang G, et al. Microstructural evolution and performance of carbon fiber-toughened $\mathrm{ZrB}_{2}$ ceramics with $\mathrm{SiC}$ or $\mathrm{ZrSi}_{2}$ additive. $J$ Adv Ceram 2018, 7: 343-351.

[13] Yu ZJ, Lv X, Lai SY, et al. $\mathrm{ZrC}-\mathrm{ZrB}_{2}-\mathrm{SiC}$ ceramic nanocomposites derived from a novel single-source precursor with high ceramic yield. $J$ Adv Ceram 2019, 8: $112-120$.

[14] Chen YT, Sun W, Xiong X, et al. Microstructure, thermophysical properties, and ablation resistance of C/HfC-ZrC-SiC composites. Ceram Int 2019, 45: 46854691.

[15] Chen J, Wang YG, Cheng LF, et al. Thermal diffusivity of three-dimensional needled $\mathrm{C} / \mathrm{SiC}-\mathrm{TaC}$ composites. Ceram Int 2011, 37: 3095-3099.

[16] Wen QB, Riedel R, Ionescu E. Solid-solution effects on the high-temperature oxidation behavior of polymer-derived (Hf, Ta)C/SiC and (Hf, Ti)C/SiC ceramic nanocomposites. Adv Eng Mater 2019, 21: 1800879.

[17] Zhang JP, Qu JL, Fu QG. Ablation behavior of nose-shaped $\mathrm{HfB}_{2}$-SiC modified carbon/carbon composites exposed to oxyacetylene torch. Corros Sci 2019, 151: 87-96.

[18] Guo SQ, Naito K, Kagawa Y. Mechanical and physical behaviors of short pitch-based carbon fiber-reinforced $\mathrm{HfB}_{2}-\mathrm{SiC}$ matrix composites. Ceram Int 2013, 39: 1567-1574.

[19] Chen YT, Sun W, Xiong X, et al. Microstructure, thermophysical properties, and ablation resistance of C/HfC-ZrC-SiC composites. Ceram Int 2019, 45: 46854691.

[20] Luo L, Wang YG, Duan LY, et al. Ablation behavior of $\mathrm{C} / \mathrm{SiC}-\mathrm{HfC}$ composites in the plasma wind tunnel. J Eur Ceram Soc 2016, 36: 3801-3807.

[21] Agte VC, Altertum H. Untersuchungen über systeme hochschmelzender carbide nebst beitr ägen zum problem der kohlenstoffschmelzung. Z Tech Physik 1930, 11: 182.

[22] Lakiza SM, Tyschenko JS, Lopato LM. Phase diagram of the $\mathrm{Al}_{2} \mathrm{O}_{3}-\mathrm{HfO}_{2}-\mathrm{Y}_{2} \mathrm{O}_{3}$ system. $J$ Eur Ceram Soc 2011, 31: 1285-1291.

[23] Huang D, Zhang MY, Huang QZ, et al. Mechanical property, oxidation and ablation resistance of $\mathrm{C} / \mathrm{C}-\mathrm{ZrB}_{2}-$ $\mathrm{ZrC}-\mathrm{SiC}$ composite fabricated by polymer infiltration and pyrolysis with preform of $\mathrm{C}_{\mathrm{f}} / \mathrm{ZrB}_{2}$. J Mater Sci Technol 2017, 33: 481-486.

[24] Yan CL, Liu RJ, Zhang CR, et al. Ablation and mechanical properties of $3 \mathrm{D}$ braided $\mathrm{C} / \mathrm{ZrC}-\mathrm{SiC}$ composites with various $\mathrm{SiC} / \mathrm{ZrC}$ ratios. Ceram Int 2016, 42: 19019-19026.

[25] Duan LY, Zhao X, Wang YG. Comparative ablation behaviors of $\mathrm{C} / \mathrm{SiC}-\mathrm{HfC}$ composites prepared by reactive melt infiltration and precursor infiltration and pyrolysis routes. Ceram Int 2017, 43: 16114-16120.

[26] Fan HB, Ravala NK, Wikle III HC, et al. HfC structural foams synthesizing from polymer precursors. In: Innovative Processing and Synthesis of Ceramics, Glasses and Composites IX. Singh NP, Bansal BG, Nair T, et al. Eds. Hoboken, NJ, USA: John Wiley \& Sons, Inc., 2012: 13-24.

[27] Wen QB, Luan XG, Wang L, et al. Laser ablation behavior of SiHfC-based ceramics prepared from a single-source precursor: Effects of Hf-incorporation into SiC. $J$ Eur Ceram Soc 2019, 39: 2018-2027.

[28] Harish DVN, Bharatish A, Murthy HNN, et al. Evaluation of nanosecond laser ablation and scratch resistance of tantalum carbide coated graphite substrates. Ceram Int 2019, 45: 22578-22588.

[29] Nisar A, Ariharan S, Venkateswaran T, et al. Effect of carbon nanotube on processing, microstructural, mechanical and ablation behavior of $\mathrm{ZrB}_{2}-20 \mathrm{SiC}$ based ultra-high temperature ceramic composites. Carbon 2017, 111: 269-282.

[30] Mungiguerra S, di Martino GD, Cecere A, et al. Arc-jet wind tunnel characterization of ultra-high-temperature ceramic matrix composites. Corros Sci 2019, 149: 18-28.

[31] Panerai F, Helber B, Chazot O, et al. Surface temperature jump beyond active oxidation of carbon/silicon carbide composites in extreme aerothermal conditions. Carbon 2014, 71: 102-119.

[32] Auweter-Kurtz M, Kurtz HL, Laure S. Plasma generators for re-entry simulation. J Propul Power 1996, 12: 1053 1061.

[33] Monteverde F, Savino R, de Stefano Fumo M, et al. Plasma wind tunnel testing of ultra-high temperature $\mathrm{ZrB}_{2}-\mathrm{SiC}$ composites under hypersonic re-entry conditions. J Eur Ceram Soc 2010, 30: 2313-2321.

[34] Monteverde F, Savino R, de Stefano Fumo M. Dynamic oxidation of ultra-high temperature $\mathrm{ZrB}_{2}-\mathrm{SiC}$ under high enthalpy supersonic flows. Corros Sci 2011, 53: 922-929.

[35] Lespade P, Richet N, Goursat P. Oxidation resistance of $\mathrm{HfB}_{2}-\mathrm{SiC}$ composites for protection of carbon-based materials. Acta Astronaut 2007, 60: 858-864.

[36] Wang YG, Ma BS, Li LL, et al. Oxidation behavior of $\mathrm{ZrB}_{2}-\mathrm{SiC}-\mathrm{TaC}$ ceramics. J Am Ceram Soc 2012, 95: 374-378.

[37] Luo L, Wang YG, Liu LP, et al. Ablation behavior of C/SiC composites in plasma wind tunnel. Carbon 2016, 103: $73-83$.

[38] Grau T, Messerschmid E. Numerical investigation of a partially ionized air flow in a plasma wind tunnel. In: Proceedings of the 7th AIAA/ASME Joint Thermophysics and Heat Transfer Conference, 1998: AIAA-98-2955.

[39] Alfano D, Scatteia L, Cantoni S, et al. Emissivity and catalycity measurements on SiC-coated carbon fibre 
reinforced silicon carbide composite. J Eur Ceram Soc 2009, 29: 2045-2051.

[40] Holcomb GR. Countercurrent gaseous diffusion model of oxidation through a porous coating. Corrosion 1996, 52: 531-539.

[41] Yang F, Gu JM, Ye LH, et al. Justifying the significance of Knudsen diffusion in solid oxide fuel cells. Energy 2016, 95: $242-246$.

[42] Savino R, de Stefano Fumo M, Silvestroni L, et al. Arc-jet testing on $\mathrm{HfB}_{2}$ and $\mathrm{HfC}$-based ultra-high temperature ceramic materials. J Eur Ceram Soc 2008, 28: 1899-1907.

[43] Caniglia S, Barna GL. Handbook of Industrial Refractories Technology: Principles, Types, Properties and Applications. William Andrew, 1992: 135.

[44] Helber B, Chazot O, Hubin A, et al. Microstructure and gas-surface interaction studies of a low-density carbon-bonded carbon fiber composite in atmospheric entry plasmas. Compos Part A: Appl S 2015, 72: 96-107.

[45] Gasch M, Ellerby D, Irby E, et al. Processing, properties and arc jet oxidation of hafnium diboride/silicon carbide ultra high temperature ceramics. J Mater Sci 2004, 39: 5925-5937.

Open Access This article is licensed under a Creative Commons Attribution 4.0 International License, which permits use, sharing, adaptation, distribution and reproduction in any medium or format, as long as you give appropriate credit to the original author(s) and the source, provide a link to the Creative Commons licence, and indicate if changes were made.

The images or other third party material in this article are included in the article's Creative Commons licence, unless indicated otherwise in a credit line to the material. If material is not included in the article's Creative Commons licence and your intended use is not permitted by statutory regulation or exceeds the permitted use, you will need to obtain permission directly from the copyright holder.

To view a copy of this licence, visit http://creativecommons.org/licenses/by/4.0/. 